\title{
The psychiatrist in the community mental health team
}

\author{
Linda Montague, Senior Registrar in Psychiatry, Glanrhyd Hospital, Bridgend, \\ Mid Glamorgan CF31 4LN
}

It was with a feeling of taking a step into only vaguely charted territory that in May 1988 I agreed to be the psychiatric member of a pilot multidisciplinary community mental health team to be set up in the South-West sector of Cardiff.

\section{The team}

The team consisted of myself, a psychologist, a social worker, an OT, a physiotherapist and three CPNs. We were all already employed full-time by the health or local authorities and were only able to devote one or two sessions a week. We were to accept referrals from a large general practice in our sector; the partners had agreed to refer to the team rather than to other existing mental health services. We could also hold team meetings and see patients on the practice premises.

\section{Realities}

A consensus on our general method of working emerged quite readily from a series of weekly meetings. We would discuss the referral letters, allocate them to team members as seemed appropriate, and then see the patient - who by general agreement had turned into a client - for an assessment interview carried out by two team members. Joint assessment would enable us to support and train those not used to doing initial assessments, and arrive at a common format for assessing and presenting clients. After assessment, the case would be discussed with the whole team, an intervention plan agreed on, and a key worker appointed to implement it. The team would review all active cases regularly. We also agreed that we would like to work in a non-hierarchical, cooperative manner, without a team leader, making decisions by consensus as far as possible. Clinical responsibility would rest with the key worker, and medical responsibility with the psychiatrist if she were key worker, otherwise with the GP. These principles were enshrined in our operational policy, which we jointly produced as a first exercise in co-operative working.

We tried to allocate cases according to workers' interests and skills, so many of the cases that I saw were those traditionally dealt with by the psychiatrist. Other team members were busy with clients requiring family therapy, anxiety management, counselling and many other forms of help. Yet other clients were not taken on by the team, but referred on to more appropriate sources of help such as a support group for sexual abuse survivors. I was able to discuss my clients with the team, gaining from different points of view and improving co-ordination of care in complex cases where several professions were involved. I was also able to listen to other team members discussing their cases and offer my own ideas on management.

At times I would re-assess clients seen by other team members if it seemed there might be major mental illness present; an elderly lady was referred with chronic anxiety and benzodiazepine dependence and seen by the psychologist and physiotherapist who felt that she was severely depressed, which I was able to confirm on seeing her myself. I instituted treatment with anti-depressant medication and she made a rapid recovery. I tried to carry out such re-assessments jointly with another team member, so that this would help other team members to recognise the symptoms which would indicate the need for a medical intervention.

As well as clinical work, we held several half or whole day meetings, some as team building exercises, others to carry out tasks such as compiling a report on the project. We also met a representative from the GP practice monthly to receive feedback on how they felt the team was working and to discuss future plans.

After a year on the team, the time came for me to leave; and to take stock of the project. The team had a steady flow of referrals; there had been few disagreements, and no disasters; and I felt that I had fitted into the team without major problems. We were providing an effective, locally based service which both the clients and the GPs were happy with, and we functioned well as a team. We were in the process of setting up or carrying out evaluations of different aspects of the service.

\section{Problems}

No money; no proper base; no secretarial support; no time; all these were overcome to some extent by a mixture of enthusiasm and ingenuity, although lack of secretarial support was a serious difficulty. 
Doubt and even hostility expressed (mainly covertly) by some outside the team caused us concern, but also united us in a determination to succeed.

Our most painful problem was the failure of one member of the team to attend team meetings or discuss allocated cases with us because of other timeconsuming commitments. Repeated prompting failed to produce any changes in behaviour, and the situation culminated in an unpleasant meeting where the team had to tell its errant member that we felt that he no longer belonged to the team. This difficult incident made us very aware of the potential problems faced by any team whose members do not agree on their mutual ways of working. If we had been fulltime workers appointed to work in the team we could not have dealt with the situation so summarily.

Uncertainty as to whom we were collectively responsible was a further difficulty here; we were individually responsible to our own professional managers, but there was no multidisciplinary body to whom we could turn should we be unable to resolve problems such as the one outlined above.

There were no serious disputes over client management, no-one had totally rejected the medical way of working out of hand, we had not become a service for the 'worried well', it did not appear that serious problems were being missed by our assessment system, and we were taking steps to audit our assessments to ensure this was so.

\section{The psychiatrist in the team}

To relinquish even a fraction of one's power and to share one's inescapable responsibilities as a doctor may be seen as threatening. To work as an equal partner rather than the automatic leader of a team is an unfamiliar role to most doctors. I agreed to work in this way because I came to feel that the team members respected my knowledge and experience of many types of mental health problems and their management. They were willing to accept that for some clients, medical treatment was an appropriate part of their care. I knew that if I gave my views on a client's management, they would be respected. This was a two-way process; I also respected the knowledge and experience of others in their fields, and recognised that non-medical interventions are effective and appropriate ways of dealing with many mental health problems. I knew that other team members were aware of the problems that require medical intervention and would always ask my advice if necessary, just as I would ask theirs.

\section{Making it work}

Setting up and working in a successful multidisciplinary team is not an easy task. Allowing adequte time for forming relationships within the team, and discussing mutual aims and fears, is vital. Developing a sense of common purpose draws the team together. The team must have sufficient contact to be a real team, not a collection of individuals working in the same building, and must truly represent all disciplines. But the three most vital ingredients are commitment, respect and trust.

\section{Acknowledgements}

I would like to thank Dr P. Williams, for arranging my attachment to the team; the GPs who provided our clients and our accommodation; and the other members of the team for their unswerving support during the year I was with them. 